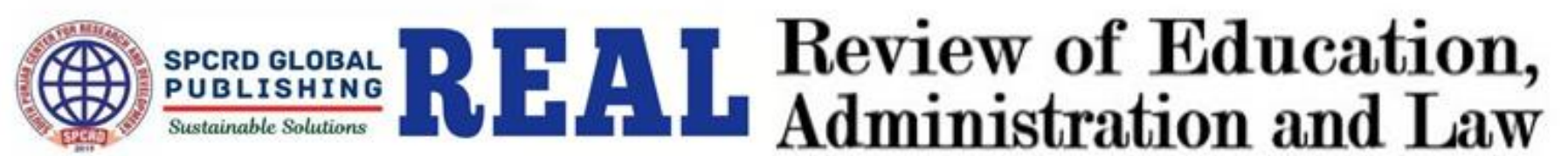 \\ Journal homepage: http://real.spcrd.org ISSN (Print): 2708-1788 ISSN (Online): 2708-3667
}

\section{Effectiveness of Traditional and Competency Based Curricula: Perspective of Graduates, Trainers and Employers}

\author{
${ }^{a}$ Ghazal Khalid Siddique, ${ }^{b}$ Huma Lodhi, ${ }^{c}$ Muhammad Anwer, ${ }^{d}$ Muhammad Khalid Zubair \\ ${ }^{a}$ Assistant Professor University of Education, Lahore, Pakistan \\ Email: ghazlKhalid@ue.edu.pk \\ ${ }^{\mathrm{b}}$ Assistant Professor University of Education, Lahore, Pakistan \\ Email: huma.lodhe@gmail.com \\ ${ }^{c}$ Assistant Professor University of Education, Lahore, Pakistan \\ Email: anwer@ue.edu.pk \\ ${ }^{\mathrm{d}}$ PhD Scholar University of Education, Lahore, Pakistan \\ Email: khalid.zubair39@yahoo.com
}

\begin{tabular}{l}
\hline ARTICLE DETAILS \\
\hline History: \\
Accepted o6 Sep 2020 \\
Available Online 30 Sep 2020 \\
\\
Keywords: \\
Competency, Competency Based \\
Curriculum, Traditional Training \\
Programs, Competency Based \\
Training, Implementation of \\
Curriculum, Perceptions
\end{tabular}

JEL Classification:

J31, C61, C69

DOI: $10.47067 /$ real.v3i2.68

\section{ABSTRACT}

Traditional training system of TVET sector is focusing on traditional procedures of learning and is based on the numbering system. Such old fashioned procedures and the numbering system are producing certificate holders who do not have proper skills to complete the tasks independently in a professional manner as per the requirements of the industry. Traditional training is not paying focus on the competency oriented workforce in Pakistan. To meet rapid technological changes and need of modern era, the approach of the TVET sector is now shifting from traditional training to Competency Based Training (CBT). The purpose of this study is to make an innovative effort in the Pakistani context, identify the perceptions of employers and graduates about traditional training and CBT programs. This study falls in the interpretivism paradigm. Phenomenological research design was utilized to conduct this study. 10 TVET trainers, 10 TVET graduates of traditional training, 10 TVET graduates of CBT and 10 employers selected through convenient sampling. Semi structured interviews were conducted from employers, trainers and both types of graduates. Thematic analysis was used for to draw the results. Results showed that graduates of competency based training programs are more competent than that of traditional training program and the employers are comparatively more satisfied with graduates of the CBT program. TVET sector should develop the curriculum according to the current demand of the industry and implement the curriculum effectively by updating the labs for the TVET graduates for better job opportunities in the industry. It is also proposed that TVET sector should shift its educational institutes from traditional training to CBT approach to meet the needs of the labour market for employers' satisfaction. Furthermore, research 
should be conducted to explore the challenges and their solutions of training provided in TVET sector and its assessment to meet the level of competency satisfaction to meet labour market needs.

(C) 2020 The authors. Published by SPCRD Global Publishing. This is an open access article under the Creative Commons AttributionNonCommercial 4.0

Corresponding author's email address: ghazlKhalid@ue.edu.pk

\section{Introduction}

The role of education in the economic development of the countries is of vital significance. The economic development of a nation is significantly associated with the technical expertise of TVET graduates. For the development of a nation, the competent TVET graduates are inevitable (Dadi, 2014). According to the prescribed curriculum criteria for vocational training designed by the Punjab Technical Education \& Vocational Training Authority (PTEVTA), traditional training consists of 20\% theory and $80 \%$ practical work. A student is eligible to get a certificate if he/she secures $40 \%$ marks in theory and $60 \%$ marks in practical. This numbering system is producing certificate holders who do not have the proper skills to complete the tasks independently in a professional manner. This is one of the reasons that unemployment is increasing even in the presence of many certificate holders (Shabbir, Shariff, Alshaibani, Faisal, \& Salman, 2018).

Traditional training system of TVET sector is focusing on conventional procedures of learning. Such procedures are not enough to meet the emerging trends of the modern era as traditional training procedure is not paying focus on competency oriented workforce. To meet rapid technological changes and need of modern era, the approach of the TVET sector is now shifting from traditional training to Competency Based Training (CBT) (NVQF, 2015). It is the dire need of the CBT system to shift the mode of curriculum from traditional to Competency Based Curriculum (CBC). Competency is termed as the ability of a person to understand and do specific tasks and duties successfully in a workplace environment (Lawler, 1994). The word "competence" was firstly used in an article written by White (1959) as a thought for performance inspiration.

The competent workforce comprises of such personnels who have skills for a specific trade and level set by the industry (Bresnahan, Brynjolfsson, \& Hitt, 2002). It is supposed that competent workforce understands the environment of the industry and contributes effectively in the productivity (Cully, 1999). CBT focuses on the competency of the graduates according to the requirement of the employer. Competency includes knowledge, skill and attitude related to a specific task (Salleh et al., 2015).

Any curriculum that is not developed systematically, that becomes static or irrelevant and will have an adverse effect on the competence of graduates (Nooruddin, 2017). TVET is one of the most the indispensable part of education, whose main aim is to produce such talented and skilled graduates as are strictly required in the society for the economic growth. Such graduates must have all possible technical and vocational concepts to be fit for the labour market (Marope, Chakroun, \& Holmes, 2015).

TVET sector is considered a strong platform for the enhancement of knowledge according to the industry requirement (Paryono, 2017). In the previous decades, a mismatch remained for a long time between the demands of the markets and the skills supplied through the technical education programme (TEP). The syllabus focused only on the theoretical knowledge and information rather 
misinformation about the real and working market instead of providing practical skills and competencies. The TVET graduates are still untrained according to the requirement of the market (Dunn-Smith, 2011). They not only create hindrance in the employment opportunities but also create problems within-employments (Ekpenyong \& Edokpolor, 2016).

Ghazi, Shahzada, Shah, Shauib, and Research (2013) conducted a research on Technical and Vocational Education at secondary level in Pakistan. The results of his study showed that there is very week linkage of institutions with industry in the Punjab. Raza, Ibrahim Khalid, and Research (2017) explored the reasons behind failure in achieving set targets of Technical Education in Pakistan. The results reflected that there is a real need to improve funding and revise curricula periodically, improve university industry linkage to increase quality of both general and technical education.

The competencies are the qualities of the graduates which are helpful to work independently in a professional way (Solomon, 2016). The sufficient knowledge, proper skills, reasonable attitudes, and appropriate experience are the elements of the competencies. It can be called the capability of achieving the success in working life. According to Brown (1994), personal competencies are integration of different performing capabilities (such as knowledge, skills, attitude, solving the problems and decision making etc) in professional working environment.

Competency Based Training (CBT) is basically a structural approach. It helps students to get such information and knowledge as is required by organization they work for. According to (Melvin, 2018), CBT is helpful for the TVET graduates to compete in the present newly invented and discovered conditions of the industry. They are trained in such a practical way that would be helpful in their furturistic tasks (Anane, 2013). Further, CBT also focuses on the achievements of the students in their workplace when they have completed their course work (Cowie, 2014). According to Boahin and Hofman (2013), industry and academic knowledge are closely related with each other in competence based training.

A systematic approach has been used to launch the CBT programs in terms of their designs, deliverance, and adaptation (NAVTTC, 2017). This is for the better job opportunity and career saving modes. This systematic approach focuses on the strong market linkages and employability for the trainees. Through Competency Based Assessment (CBA), the learners or trainees are assessed when they have completed their course work of training. Recognition of Prior Learning/Recognition of Current Competencies (RPL/RCC) recognizes trainees' skills outside the formal system (Pakistan Technical \& Vocational Education \& Training Reform, 2020).

According to Boahin and Hofman (2014) effectiveness of curriculum depends on curriculum implementation. Wesselink (2010) suggested that student's perceptions can influence the nature and quality of the teaching learning process. Student's perceptions of the meaningful learning environment can determine the implementation and learning results. According to Maor and Fraser (1996) the perceptions of both the students and teachers can be important for optimizing teaching learning process. Teachers' perceptions have proven to be useful variables in investigating teaching learning process and are interesting points to seize upon the interpretation of teachers and in-staff development (Wesselink, 2010).

Competency Based Training (CBT) is a new concept in the field of technology in Pakistan that is the revised version of traditional training. This study is an effort to compare the traditional training 
program with the CBT program that will highlight the pros and cons of both the training approaches. This comparison will provide a road map to make a paradigm shift from traditional training to the CBT.

Objective of the current research was as to find out trainers', graduates' and employers' perceptions about the effectiveness of traditional and competency based curricula.

\section{Methodology and Data Collection}

Philosophical paradigm of current study was interpretivism. The Researcher used phenomenological research design for this research to identify the phenomenon in a better way (Creswell, 2014; Greene, 2007; Johnson \& Onwuegbuzie, 2004).

The sample of the study was comprised of 10 TVET trainers, 10 TVET graduates of traditional training, 10 TVET graduates of CBT and 10 employers selected through convenient sampling. Semi structured interviews were conducted from employers, trainers and both types of graduates. By considering the nature of the study, interview protocols were developed by the researcher to know the perceptions about traditional training and CBT from TVET trainer/teachers, TVET graduates and employers.

\subsection{Data Analysis and Findings}

The researcher conducted interviews from the TVET trainers, graduates and employers with the help of semi-structured interview. The researcher took help from the teachers of various institutes to identify the graduates as respondents and especially purposefully those employers were identified for interview where both graduates (from traditional training and CBT) were employed. The researcher conducted semi-structured interviews from selected respondents and saved in audio with the permission of the respondents and after return to the workplace the detail responses of interviewees were transcribed.

The recorded interviews were text transcribed, that was basis for analysis of qualitative data. For establishing of meaningful patterns, thematic analysis was utilized through the coding process.

\subsection{Perceptions of Traditional Graduates}

Interviewees graduated through traditional training were not satisfied with the theoretical knowledge provided to them during the training. They expressed that knowledge delivered during training was not so updated to fulfil the industry requirement or the teacher did not cover the whole course contents during training. The reason they told that they were asked to prepare selected topics for examination point of view or due to the shortage of time some topics were left.

The perceptions of graduates regarding skills provided to them during the traditional training are that there were certain gaps. They expressed a gap between the available machinery \& equipment in institute and working place in the market. Few of them were satisfied in terms of skill as a result of training.

Most of the participants expressed that the required attitude was not developed through the institutional training. There was a gap which needs improvement. When they entered the industry, they faced lot of difficulties due to improper attitude. There was almost similar response of the respondents about the attitude or work ethics that it was not focused during training or the safety equipment was not available or short. 
Overall response of the traditional graduates about the traditional training was not optimistic as they faced difficulty in grooming themselves according to the market. They expressed freely that they were not enough competent according to the demand of market/industry and they had to work hard to be adjusted or able to fulfil the workplace requirements.

\subsection{Perception of CBT Graduates}

The interviewees were looked satisfied with the knowledge provided to them during the competency based training. Most of them expressed positive views towards the knowledge provided to them as they found it aligned with the demand of industry. But it was observed that in some of the institutes available equipment was short or old. Almost all the respondents shared that the curriculum was updated and the whole curriculum was covered during training. A candidate must complete all the pre-requisites of formative assessment to qualify for the summative assessment. So there is no option of selected study.

Participants of the study told that skills which were provided during training were fulfilled the work place requirements. Participants appreciated the relevant task performing activities, experiential learning and simulation. The institutional training provided to the graduates was as per the demand of the industry. However, some of the participants pointed out the fact that industry is having more latest machines than they have used during institutional training. So, machinery and technology of the institutes must be upgraded.

The graduates expressed that importance of attitude is more than even skill and knowledge in market. Further interviewees said that the attitude developed during the training meets the industry and job requirement.

Overall response which participants provided, that they are satisfied with the training as it made them competent to meet their job requirements. They were able to cope with all kinds of situations occurring at workplace. However, few of them still found a gap between the industry and training competencies due to the shortage of latest machinery in the institute.

\subsection{Perception of Trainers}

The results of the trainers' interviews indicated that there is difference in traditional training program and CBT program regarding curriculum implementation. The students of CBT are significantly more competent in all aspects (knowledge, skills and attitude) than the students of traditional training program, because of continuous and mandatory formative assessment whose record is maintained for summative assessment. But there is no such requirement for the students of the traditional training. The other indicator was the curriculum development. They told that the curriculum of CBT is comparative more aligned with the demand of industry. But during implementation of both types of curriculum, the curricula compliant labs are the most challenging problem for the skill development of the students.

\subsection{Perception of Employers}

The results of interviews from employers indicated the difference in both types of graduates. Most of them presented their perceptions that CBT graduates are better than traditional graduates in respect of knowledge, skill and attitude. They admitted this fact that CBT graduates have such practical knowledge, skills, attitude which is relevant to the industry. They further stated that CBT graduates have better competency. Most of employers stated that traditional trainees are unaware of the 
standards and industry requirement. On the basis of aforementioned differences, the employers prefer to hire CBT graduates over traditional system graduates.

\section{Discussion}

Overwhelming literature is available on the concerned topic in African context. Whereas the present study is an innovative effort in Pakistani scenario. This research aimed to identify the curriculum development process along with its implementation and perceptions of employers, TVET teachers and TVET graduates of traditional training and CBT program. The Present study is an effort to add knowledge to existing literature in the relevant field.

The historical comparative of the current study indicates that no similar or contradictory research has been found that attempted to compare CBT with traditional training programs.

The outcome of the present study indicated that learning outcomes of CBT are better than that of the traditional training. Similarly, instructional strategies used by teachers of CBT program were more effective than that of the traditional training program. Students of CBT program have better problem solving skills and personal qualities as compared to the students of traditional training program.

The results of current study reflected that in CBT students were more competent than that of traditional training, which are concurrent with the results of the study conducted by (Ndile, 2018).

The result indicates that teaching and learning (presentation) process was more effective in CBT programs and teachers who belonged to CBT used learning materials in better ways as compared to the teachers of traditional training programs. It was also supported by Ndile (2018) as results of his study showed that teachers working in CBET programs were more skilled and gave their best performance to meet the criteria/ requirement of market as compared to the traditional teachers. But the result of Dadi (2014) were contradictory to the results of present study as he claimed that teachers faced problems in practicing basic principle and remained unable to define competencies in proper manner in teaching learning process. The reasons behind this contradiction may be many as the contexts of both the studies are different. The present study is conducted in Pakistani circumstances while Dadi (2014) conducted his study in the Ethiopian scenario.

\section{Conclusion}

The results of qualitative data showed that the curriculum developed for competency based programs is more aligned with the industry demand. CBT graduates are more competent instead of traditional graduates. The knowledge of CBT graduates is better and fulfill the market needs due to its regular and mandatory module wise formative assessment, so no chance for selective study, which makes them better. The skills of both graduates fulfill the needs of the market. The attitude of CBT graduates is far better than that of traditional graduates.

In view of foregoing conclusion and discussion, some recommendations have been suggested. TVET sector should adopt the latest and worldwide recognized assessment methods for their students to ensure the achievement of the desired level of competency as per the demand of the industry. TVET sector should implement the curriculum in an effective way and make it more useful by upgrading the labs for the TVET graduates to get better job opportunities in the industry. Research should be conducted to explore the challenges and their solutions of training provided in TVET sector especially development as well as implementation of curriculum to meet labour market needs. Research should be 
conducted to identify the effect of teacher training and Assessment on the competency of the students.

\section{References}

Anane, C. A. J. E. r. i. (2013). Competency based training: Quality delivery for technical and vocational education and training (TVET) institutions. 2(2), 117-127.

Boahin, P., \& Hofman, A. (2013). A disciplinary perspective of competency-based training on the acquisition of employability skills. 65(3), 385-401.

Boahin, P., \& Hofman, W. A. J. I. J. o. E. D. (2014). Perceived effects of competency-based training on the acquisition of professional skills. 36, 81-89.

Bresnahan, T. F., Brynjolfsson, E., \& Hitt, L. M. (2002). Information technology, workplace organization, and the demand for skilled labor: Firm-level evidence. The Quarterly Journal of Economics, 117(1), 339-376.

Brown, M. (1994). An introduction to the discourse on competency-based training (CBT) in Deakin University Course Development Centre (Ed.), A collection of readings related to competencybased training (pp. 1-17). Victoria, Australia: Victorian Education Foundation, Deakin University. In.

Cowie, W. (2014). What Is Competency Based Training? Retrieved from https://www.inspireeducation.net.au/blog/training-and-assessment/what-is-competencybased-training/

Creswell, J. W. (2014). A concise introduction to mixed methods research: SAGE publications.

Cully, M. (1999). Britain at work: As depicted by the 1998 workplace employee relations survey: Psychology Press.

Dadi, L. (2014). Effectiveness of Competency-based TVET Curriculum in Ethiopia: The Case of TVET Institutions of Oromia Regional State (Ph. D. Thesis) Addis Ababa University. Ethiopia,

Dunn-Smith, P. (2011). Competency based Training (CBT) Promotes Education and Training in TVET institutions for the world of Work.

Ekpenyong, L. E., \& Edokpolor, J. E. (2016). WINNING THE WAR AGAINST UNEMPLOYMENT AND POVERTY IN NIGERIA: IS THERE A ROLE FOR TVET-PRIVATE SECTOR PARTNERSHIP? , 1(2), 125-132.

Ghazi, S. R., Shahzada, G., Shah, M. T., Shauib, M. J. J. o. E., \& Research, S. (2013). Teacher's professional competencies in knowledge of subject matter at secondary level in Southern Districts of Khyber Pakhtunkhwa, Pakistan. 3(2), 453.

Greene, J. C. (2007). Mixed methods in social inquiry (Vol. 9): John Wiley \& Sons.

Johnson, R. B., \& Onwuegbuzie, A. J. J. E. r. (2004). Mixed methods research: A research paradigm whose time has come. 33(7), 14-26.

Lawler, E. E. (1994). From job-based to competency-based organizations. Journal of Organizational Behavior, 15(1), 3-15. doi:10.1002/job.4030150103

Maor, D., \& Fraser, B. J. J. I. J. o. S. E. (1996). Use of classroom environment perceptions in evaluating inquiry-based computer-assisted learning. 18(4), 401-421.

Marope, P. T. M., Chakroun, B., \& Holmes, K. (2015). Unleashing the potential: Transforming technical and vocational education and training: UNESCO Publishing.

Melvin, E. (2018, June 9, 2018). Getting Started With Competency-Based Training (CBT). Retrieved from https://elearningindustry.com/competency-based-training-cbt-getting-started

NAVTTC. ( 2017). National Vocational Qualification Framework version 2. Retrieved from https://tvetreform.org.pk/under-construction/\#

Ndile, L. M. (2018). The Influence of competency based technical training on youth employability: a study of technical training institutions in Nairobi County. Strathmore University,

Nooruddin, S. (2017). Technical and Vocational Education and Training for Economic Growth in 
Pakistan. 4(1), 130-141.

NVQF, N. P. (2015). National Vocational and Technical Training Commission ( NAVTTC ) Pakistan National Vocational Qualifications Framework ( NVQF ). 1(March 2015).

Pakistan Technical \& Vocational Education \& Training Reform, T. R. (2020, January 26). Competency Based Training and Assessment (CBT \& A). Retrieved from https://tvetreform.org.pk/competency-based-training-and-assessment-cbt-a/

Paryono. (2017). The importance of TVET and its contribution to sustainable development. Paper presented at the AIP Conference Proceedings.

Raza, A., Ibrahim Khalid, M. J. B. o. E., \& Research. (2017). Obstacles in the Enhancement of Technical Education in Pakistan: Views and Reviews. 39(1), 117-127.

Salleh, K. M., Khalid, N. H., Sulaiman, N. L., Mohamad, M. M., Sern, L. C. J. P.-S., \& Sciences, B. (2015). Competency of adult learners in learning: application of the iceberg competency model. 204, 326-334.

Shabbir, M. S., Shariff, M. N. M., Alshaibani, Y. H., Faisal, M., \& Salman, R. J. A. o. E. J. (2018). Entrepreneurship and Skills Development for Socioeconomic Growth; Present Landscape and Future Agenda for Pakistan. 24(3), 1-12.

Solomon, G. H. (2016). Towards competence-based technical-vocational education and training in Ethiopia. Wageningen University,

Wesselink, R. (2010). Comprehensive competence-based vocational education: The development and use of a curriculum analysis and improvement model.

White, R. W. (1959). Motivation reconsidered: The concept of competence. Psychological Review, 66(5), 297-333. doi:10.1037/hoo40934 